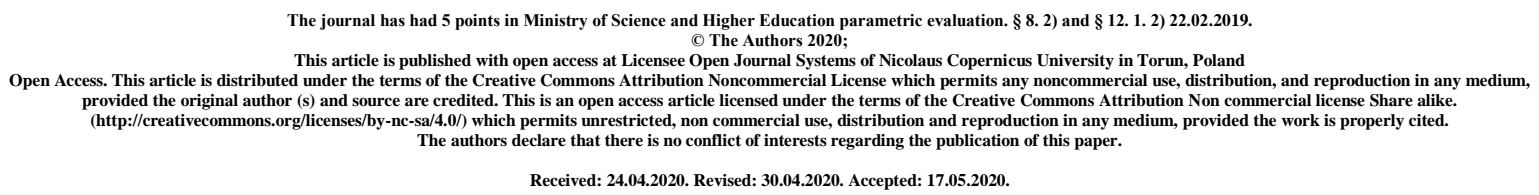

\title{
Positive effects of Dog Assisted Therapy in the Pediatric Population
}

\author{
Pawluczuk Paulina $^{1}$, Kusz Monika ${ }^{1}$, Maślak Agnieszka ${ }^{1}$, Alzubedi Adam ${ }^{2}$, Polski Pawel ${ }^{2}$ \\ 1. Department of Paediatric Nephrology, Medical University of Lublin \\ 2. Department of General and Transplant Surgery and Nutritional Treatment, Medical \\ University of Lublin
}

\begin{abstract}
Dog Assisted Therapy is a prevalent part of therapeutic process in pediatric population. It is a modern and constantly developing intervention. Dog Assisted Therapy is utilized with pervasive development disorders. Most of studies confirmed that Autistic Spectrum Disorder, Down Syndrome or Cerebral Palsy may benefit from Dog Assisted Therapy. It is important to emphasise the role od Dog Assisted Therapy in improving children mental and physical development.
\end{abstract}

Key worlds: Dog Assisted Therapy; pediatrics,

\section{Introduction}

Animal Assisted Therapy (AAT) is a type of intervention that incorporates a trained animal. AAT is considered a modern improvement of rehabilitation and treatment of several children's disorders ${ }^{[1]}$. Besides dogs (Dog Assisted Therapy-DAT) animals such as horses, 
cats or rabbits are used. ${ }^{[2]}$ DAT can be effective not only in rehabilitating children suffering from Autism Spectrum Disorder (ASD), Down's Syndrome, Cerebral Palsy, but also in pediatric palliative care. ${ }^{[1]}$

Dogs come from the Euroasian wolfs. ${ }^{[3]}$ The domestication of the dog commenced over 15,000 years ago and took place in Iran, Palestine and Siberia. At first people had dogs mainly as guards or help in hunting.

Nowadays special taming makes dogs able to help people in many ways. Because dogs' sense of smell is more sensitive than humans', it is used by the police or military to search for drugs, bombs or people. Many people use dogs to guard their houses, possession, warehouses. Not only they warn people against rubbery but also alert people before hypoglycaemic shock [4] or epileptic seizure. The other functions of the dogs are: herding, dogs leading and therapeutic. Most people own dogs as a companion animal, sometimes they treat dog as a family member. In United States circa 69.9 million households have a dog. ${ }^{[5]}$ It is indicated that people who have been in the company of a dog since childhood are more caring, resistant to stress and have less emotional problems. ${ }^{[5,6]}$ Some researches indicate that a pet owner has extended life expectancy and a higher level of serum oxytocin, serotonin, prolactin. ${ }^{[5]}$ Dogs reduce stress, anxiety, agoraphobia and help to improve verbal communication. ${ }^{[6]}$ The contact with a dog has positive effects such as reducing cortisol level, blood pressure and keeping us fit.

First historical sources about Animal Assisted Therapy came from the ancient Greeks. For example Hippocrates described positive effects of horse riding on humans. During The 18th century in Bethel, Germany animals have been used in The therapy of mentally ill for the very first time. ${ }^{[7]}$ In 1964 American psychiatrist Boris Levison found out that children suffering from Autistic Spectrum Disorder were able to communicate with a dog even though they weren't able to contact the other humans. He used the name "pet therapy" for the first time in his article "The dog as the co-therapist". ${ }^{[7]}$ After that the bond between animals and humans has become a frequent subject of research. In 1977 in the USA Delta Society was founded (in 2012 the name has changed to Pet Partners), the organization aimed at training pets, popularization of the AAT and research positive effects of AAT. ${ }^{[7]}$ It is the most important organization of those dealing with dog therapy. Delta Society created the definition and divided Animal Assisted Intervention into two parts: Animal Assisted Therapy (AAT) and Animal Assisted Activities (AAA). AAT is a planned intervention, designed for specified diseases, in which an animal is an integral part of therapy. During AAT professional therapist's presence is necessary, each day of the therapy has a definite goal. AAA's work consists of visiting the people in need by a volunteer with an animal, and promoting actions to raise quality of life through the contact with a pet. In contrast to AAT, AAA does not require a professional therapist, plan and specific therapy goal. Over time in many countries similar organizations have been founded. In Europe Dog Assisted Therapy standards are created by Assisted Dog Europe(AEDs). ${ }^{[7]}$ AEDs additionally distinguishes the third part of AAI Animal Assist Education(AAE). AAE is meant as an intervention where the animal-human team improves the human cognitive function by education programs.

Dog Assisted Therapy is considered as a prevalent part of the therapeutic process in pediatric population. Patience, gentleness, friendliness, calmness (even in an exceptional situation like a sudden noise), balanced nature are the features that every therapist dog should have. ${ }^{[7,8]}$ The 
Golden Retriever, Labrador Retriever, Cavalier King Charles Spaniel are the most frequently used dog breeds ${ }^{[8,9]}$. DAT consists of several actions, such as for instance: touching, brushing, feeding, issuing commands, walking the dog on a leash and hugging. ${ }^{[7]}$ There are few contraindications to Dog Assisted therapy such as: asthma or respiratory problems, pet-dander allergy, fear of animal. ${ }^{[5,10]}$ Not only children but also many social groups may achieve benefits from DAT, for instance psychiatric patients, war veterans (as a treatment of Posttraumatic Stress Disorder), prisoners or elderly people ${ }^{[11]}$.

\section{Autism spectrum disorder}

Autism spectrum disorder (ASD) is a complex condition which includes difficulties in social interactions, interest restrictions, problems with communication. ${ }^{[12]}$ ASD has several symptoms such as: communication delay, reparative movements (e.g. hand clapping), limited eye contact, narrow interests, constrained feelings sharing, overreactions to sound and difficulties with the imaginary play. ${ }^{[13]}$ ASD consists of autism, Asperger syndrome and atypical autism. In order to fulfil the diagnostic requirements the symptoms of autism have to come out in the early childhood. The etiology of ASD reminds unknown. Genetic factors are suspected because of the risk increase if a family member has ASD, however the precise gene hasn't been found yet. ${ }^{[14]}$ The sex is an important risk factor: the male to female ratio is estimated as 4:1 for the classic autism. ${ }^{[15]}$ Furthermore, such factors as a stressful experience, maternal conditions like diabetes, hypertension or infections, advanced parental age, low birth weight and preterm delivery are indicated. ${ }^{[16]}$ There is no perfect therapy of ASD. Various therapies of ASD do exist, nevertheless they should be highly individualized. Children suffering from ASD may benefit from the Dog Assisted Therapy. DAT increases self-esteem, social interactions in children with $\mathrm{ASD}^{[17,18,19]}$. DAT may change children's behavior by reducing anxiety, anger, emotional outbursts and repetitive behaviors. ${ }^{[1]}$ Children willingly talk to a dog during a therapy, thus affecting their own verbal interactions. Not only they express themselves to a dog, but also have a conversation with a therapist about the animal. All these activities provide to improving verbal communication and social interactions. ${ }^{[1]}$

\section{Down syndrome}

Down syndrome (DS) is a disease caused by the simple trisomy of chromosome 21 , translocation trisomy or mosaic trisomy. ${ }^{[20]}$ The symptoms include facial dysmorphism, cardiac defects, thyroid function abnormalities often leading to nutrition problems like obesity. ${ }^{[20]}$ Additionally children with DS have a higher risk of leukemia. Beside physical defects, the clinical manifestation of the DS are: impaired intellectual development, delays in language skills, behavioral problems like hyperactivity, impulsivity, higher risk of depression or anxiety. ${ }^{[1,18,21]}$ Dog assisted therapy is considered to be effective in reducing behavioral problems, anxiety and hyperactivity. ${ }^{[18]}$

\section{Cerebral palsy}

Cerebral palsy (CP) is a non-progressive neurological condition which includes heterogeneous limitation of motor functions. ${ }^{[22]} \mathrm{CP}$ is a risk factor for mental disturbance like depression, aggression, social withdrawal, thus complex therapy is required. ${ }^{[22]}$ Rehabilitation in CP should improve children's movements and be adapted individually to a patient. The 
positive effects of DAT in cerebral palsy are multidirectional. First of all, the contact with a

dog improves mood and motivation, calms one down. ${ }^{[10]}$ Secondly, dogs help with gait control, improving coordination and muscle building. ${ }^{[1,10]}$

\section{Pediatric palliative care}

The aim of pediatric palliative care is not to cure a disease but to increase the quality of life, reduce pain and anxiety. Oncological, genetic and metabolic diseases are examples of lifelimiting conditions. In this group congenital malformation are also included. To reduce an anxiety traditional pharmacological anxiolytic are often used, but the serious side effects of treatment pose as disadvantage of such a solution. ${ }^{[5]}$ Positive effects of the human-dog bond are indicated, thus DAT started to be a part of pediatric palliative care. DAT decreases stress and anxiety levels, concomitant to incurable diseases. ${ }^{[5,23]}$ There are no explicit data about reducing pain, but researches do indicate that Animal Assisted Therapy seem to distract children from pain-related condition. ${ }^{[2]}$ The important feature of DAT in pediatric palliative care is to reduce loneliness. In that group of children special contraindications of Animal Assisted Therapy are distinguished, such as neutropenia, tuberculosis, recent surgery, colonization by Methicyllin-resistant Staphylococcus aureus or Clostridium difficile. ${ }^{[5]}$

\section{Conclusion}

Dog Assisted Therapy is a important type of intervention in pediatric population, which surely should be developed. Most children benefit enormously during DAT. Further researches about DAT are needed, to improve and popularize such method of therapy.

\section{References}

1. Jesús David Charry-Sánchez, Iván Pradilla, Claudia Talero-Gutiérrez; Effectiveness of Animal-Assisted Therapy in the Pediatric Population: Systematic Review and MetaAnalysis of Controlled Studies Journal of Developmental \& Behavioral Pediatrics: September 2018 - Volume 39 - Issue 7 - p 580-590

2. Ng Zenitson et all Describing the Use of Animals in Animal-Assisted Intervention Research. J Appl Anim Welf Sci. 2019 Oct-Dec;22(4):364-376

3. Fabio Verginelli, Cristian Capelli, Valentina Coia, Marco Musiani i inni. Mitochondrial DNA from Prehistoric Canids Highlights Relationships Between Dogs and South-East European Wolves. „Molecular Biology and Evolution”. 22 (12), s. 2541-2551

4. Wells DL. Dogs as a diagnostic tool for ill health in humans. . Altern Ther Health Med. 2012 Mar-Apr;18(2):12-7.

5. Gilmer MJ, Baudino MN, Tielsch Goddard A, Vickers DC, Akard TF. Animal-Assisted Therapy in Pediatric Palliative Care. The Nursing Clinics of North America. 2016 Sep;51(3):381-395.

6 . Nancy R. Gee, Shelly L. Harris Kristina L. Johnson; The Role of Therapy Dogs in Speed and Accuracy to Complete Motor Skills Tasks for Preschool Children; Anthrozoos A Multidisciplinary Journal of The Interactions of People \& Animals 20(4):375-386

7. D Jagielski, A Jagielska, A Pyszora; Dogoterapia- historia, założenia, cele. Propozycja zastosowania w opiece paliatywnej; Medycyna Paliatywna w Praktyce, 2014 8, 4, 163-167 
8. Janina Filozof; Dogoterapia?:co to jest?; Polskie Stowarzyszenie na Rzecz Osób z Upośledzeniem Umysłowym, 2004

9. Fine, Aubrey H., ed. Handbook on animal-assisted therapy: Foundations and guidelines for animal-assisted interventions. Academic press, 2019.

10. Yap E, Scheinberg A, Williams K.; Attitudes to and beliefs about animal assisted therapy for children with disabilities. Complement Ther Clin Pract. 2017 Feb;26:47-52

11. Bachi K,Parish-Plass N; Animal-assisted psychotherapy: A unique relational therapy for children and adolescents; Clin Child Psychol Psychiatry. 2017 Jan;22(1):3-8

12. World Health Organization. International Classification of Diseases; Diagnostic Criteria for Reserarch, 10th ed. Geneva: World Health Organization, 1993

13. Sanchack KE, Thomas CA.; Autism Spectrum Disorder: Primary Care Principles.; Am Fam Physician. 2016 Dec 15;94(12):972-979.

14. Matthew W. State The Genetics of Child Psychiatric Disorders: Focus on Autism and Tourette Syndrome; Neuron Volume 68, Issue 2, 21 October 2010, Pages 254-269

15. Baron-Cohen S, Lombardo MV, Auyeung B, Ashwin E, Chakrabarti B, Knickmeyer R Why Are Autism Spectrum Conditions More Prevalent in Males? PLoS Biol 9(6): e1001081.

16. Patterson PH. Maternal infection and immune involvement in autism. Trends Mol Med. 2011;17(7):389-394. doi:10.1016/j.molmed.2011.03.001

17. Berry A, Borgi M, Francia N, Alleva E, Cirulli F. Use of assistance and therapy dogs for children with autism spectrum disorders: a critical review of the current evidence. Journal of Alternative and Complementary Medicine 2013; 19(2): 73-80.

18.Griffioen RE, van der Steen S, Verheggen T, Enders-Slegers MJ, Cox R. Changes in behavioural synchrony during dog-assisted therapy for children with autism spectrum disorder and children with Down syndrome. J Appl Res Intellect Disabil. 2020 May;33(3):398-408. doi: 10.1111/jar.12682. Epub 2019 Dec 6.

19.O'Haire M.;Research on animal-assisted intervention and autism spectrum disorder, 20122015. . Appl Dev Sci. 2017;21(3):200-216. doi: 10.1080/10888691.2016.1243988. Epub 2017

Feb 23

20. Mazurek D, Wyka J. Down syndrome--genetic and nutritional aspects of accompanying disorders. Rocz Panstw Zakl Hig. 2015;66(3):189-94.

21.Grieco J, Pulsifer M, Seligsohn K, Skotko B, Schwartz A.; Down syndrome: Cognitive and behavioral functioning across the lifespan. Am J Med Genet C Semin Med Genet. 2015 Jun;169(2):135-49. doi: 10.1002/ajmg.c.31439. Epub 2015 May 18.

22. Elmaci DT, Cevizci S. Dog-assisted therapies and activities in rehabilitation of children with cerebral palsy and physical and mental disabilities. Int J Environ Res Public Health. 2015;12(5):5046-5060. Published 2015 May 12. doi:10.3390/ijerph120505046

23. Chubak J, Hawkes R.; Animal-Assisted Activities: Results From a Survey of Top-Ranked Pediatric Oncology Hospitals. J Pediatr Oncol Nurs. 2016;33(4):289-296. doi:10.1177/1043454215614961

24. Sobo EJ, Eng B, Kassity-Krich N.; Canine visitation (pet) therapy: pilot data on decreases in child pain perception. J Holist Nurs. 2006 Mar;24(1):51-7. 